\title{
Quiet debut for the double helix
}

\author{
Robert Olby
}

Department of the History and Philosophy of Science, 1017 Cathedral of Learning, University of Pittsburgh, Pittsburgh, Pennsylvania 15260, USA

(e-mail: olbyr+@pitt.edu)

Past discoveries usually become aggrandized in retrospect, especially at jubilee celebrations, and the double helix is no exception. The historical record reveals a muted response by the scientific community to the proposal of this structure in 1953. Indeed, it was only when the outlines appeared of a mechanism for DNA's involvement in protein synthesis that the biochemical community began to take a serious interest in the structure.

\begin{abstract}
“... we may expect genetic chemistry to become in timean integrating corefor cellular

biochemistry." Robert Sinsheimer, in a lecture delivered at the California Institute of Technology, 1956 (published in ref. 1, p. 1128).
\end{abstract}

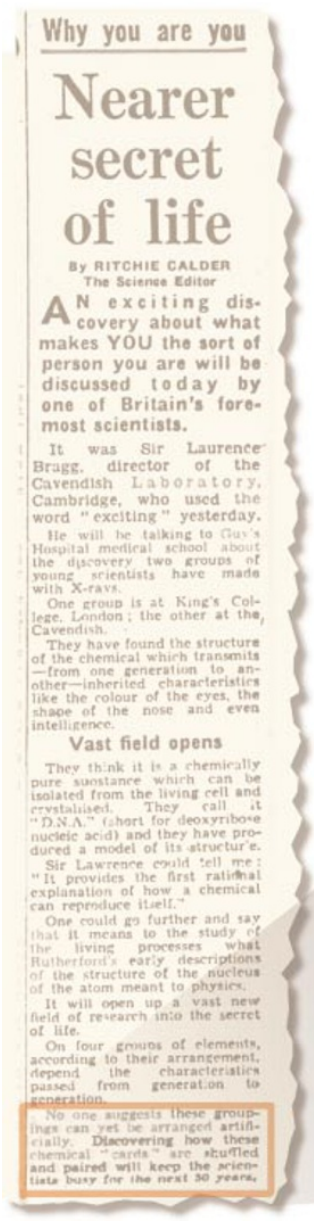

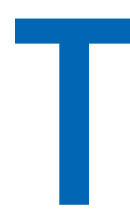

o recall the year 1953 is to visit — and for some of us to revisit — another world, when Nature did not use the abbreviation DNA for deoxyribonucleic acid. In June that year, Elizabeth II, Queen of the United Kingdom, was crowned amidst much pomp and ceremony. In March, British scientists prepared to construct an atomic power station by the Calder River. Two months later, Mount Everest was conquered. At the University of London my biochemistry teacher enthused about Frederick Sanger's success in the first sequencing of the units of a protein, insulin. But deoxyribonucleic acid (DNA) was not even mentioned. Yet in 1953 Nature published seven papers on the structure and function of $\mathrm{DNA}^{2-8}$, but only one national British newspaper - the News Chronicle referred to the double helix ${ }^{9}$ (see facsimile below).

\section{Reception to the double helix}

Fifty years on it is hard to believe the double helix had such a lukewarm reception. But turn to Nature and to Science in the 1950s and what do we find? Figure 1 records the number of papers in Nature reporting on any aspects of DNA, and of these the number that mention the Watson-Crick model or cite any of the 1953 papers on DNA structure. Through the decade Nature's volumes increased in size, and in 1960 the number of volumes published per year was doubled. This increase was accompanied by an increase in the number of papers on some aspect of DNA, but references to the double helix did not increase. The pattern of citation in Science is similar.

At the time the structure of DNA was discovered, there was already a considerable ongoing programme

Ritchie Calder's report on the discovery of the structure of DNA on page 1 of the News Chronicle, 15 May 1953.

No one suggests these groupings can yet be arranged artificially. Discovering how these chemical "cards" are shuffled and paired will keep the scientists busy for the next 50 years. of research on DNA (see time line in Box 1). These studies include the physical properties of DNA, methods of extraction, and whether the content and composition of DNA is the same for all the cells of the same organism. Also discussed were the damaging effects of ultraviolet light and ionizing radiation on DNA, and differing views over the involvement of nucleic acids in protein synthesis.

Researchers working on DNA at that time were principally biochemists and physical chemists, and their institutional locations and funding were chiefly medically related. Their interests and means of support related to two main concerns of the time the action of 'mutagens' (agents that cause mutations in DNA), a subject important to the international debate on the effects of ionizing radiation and radioactive materials (see article in this issue by Friedberg, page 436), and the nature of protein synthesis, of great interest to biochemists in the light of its importance in growth and nutrition, in addition to cancer research.

In the light of the muted reception of the structure, let us take a different angle and ask what justification was there in the 1950s for giving the DNA double helix more than passing attention? At the time, most scientists reading Nature viewed DNA as a 'conjugated protein', owing to its association with protein; it was important as such, but not in its own right. This was despite the remarkable work of Oswald Avery, Colin MacLeod and Maclyn McCarty in 1944 (ref. 10; and see article in this issue by McCarty, page 406), followed by $\mathrm{Al}$ Hershey and Martha Chase's demonstration in 1952 (ref. 11) that most of the material entering a bacterium from an infecting bacterial virus is nucleic acid not protein. These studies made DNA look very much like the hereditary material.

\section{Connecting structure to function}

More information was needed to convince the scientific community. What was there about the chemistry of DNA to justify its role in inheritance? An answer came with the structure put forward by Watson and Crick. Chief among its "novel features" of "considerable biological interest" ${ }^{2}$, Watson and Crick described the pairing of the bases, where adenine forms hydrogen bonds with thymine, and guanine with cytosine. This pairing, they wrote, "immediately suggests a possible copying mechanism for the genetic material." Expanding on this in a subsequent paper appearing in Nature a month later, they wrote of DNA: "Until now, however, no evidence has been 


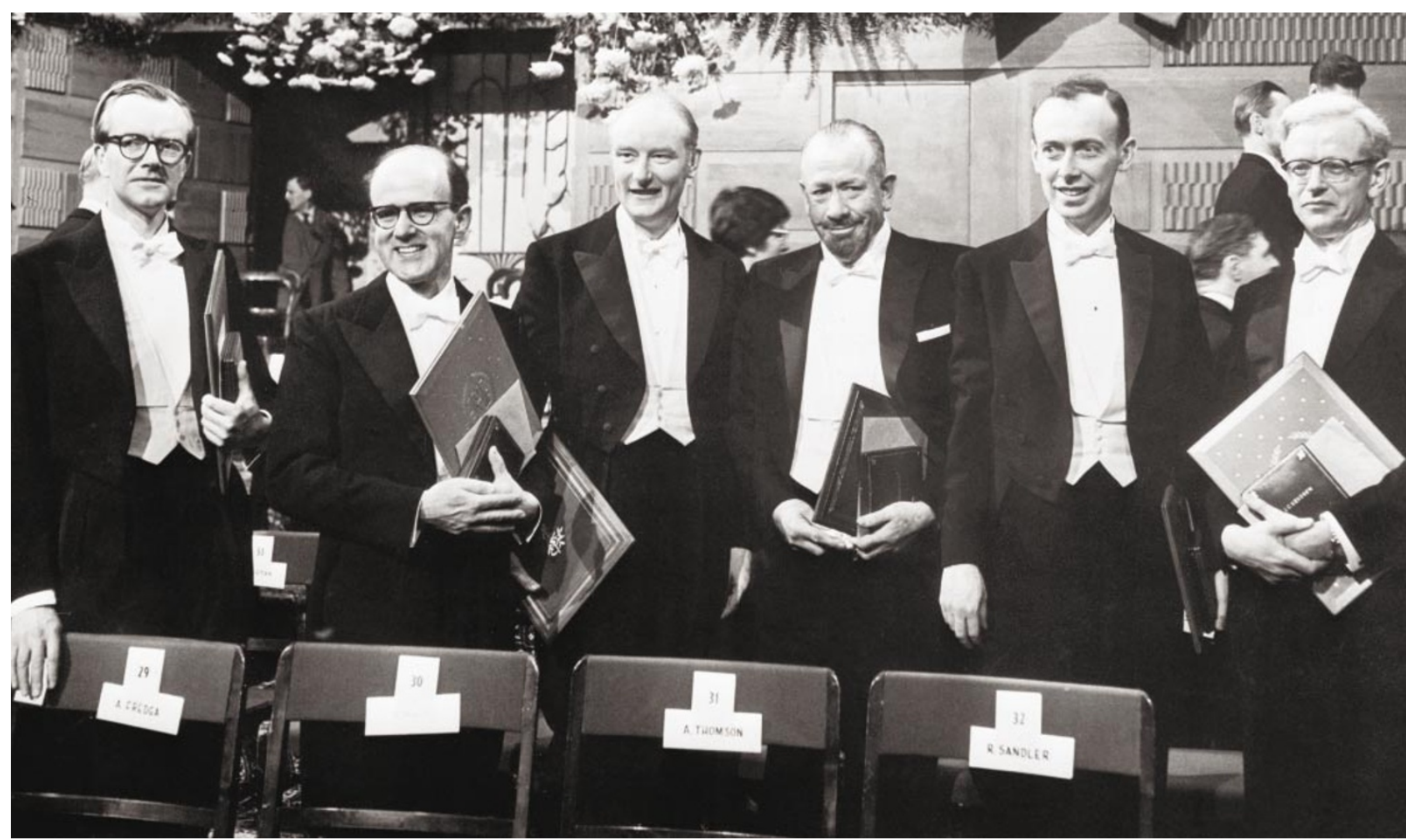

presented to show how it might carry out the essential operation required of a genetic material, that of exact self-duplication." ${ }^{5}$

With these words Watson and Crick claimed their priority on a mechanism for DNA replication, but admitted there were problems with their scheme: how do the chains unwind and separate "without everything getting tangled" ? What is the exact mechanism by which gene duplication occurs? How does the genetic material "exert a highly specific influence on the cell"12 when the sequence of bases assumed to encode the specificity is on the inside of the helical molecule?

The 'unwinding problem' dominated much of the early discussions that followed the discovery of the DNA structure. In 1953, Watson and Crick admitted it was "formidable" 12 , but support for their structure came in 1958, when Matthew Meselson and Franklin Stahl proved the semi-conservative nature of DNA replication ${ }^{13}$ : each of the two new daughter DNA molecules formed during DNA replication consists of one strand from the original parent molecule and a new strand synthesized from the parent strand, which served as a template. This confirmed Watson and Crick's theoretical prediction from the structure that replication would proceed in a semi-conservative manner. Later that same year, Arthur Kornberg announced the partial purification of an enzyme that catalyses DNA synthesis later called DNA polymerase $^{14}$. This first linked enzymology to the double helix, for not long thereafter Kornberg provided biochemical evidence that DNA polymerase synthesizes new strands from opposite directions of the two chains of the molecule ${ }^{15}$.

In 1957, Crick defined biological 'information' as the sequence of the bases in the nucleic acids and of the amino acids in proteins, and proposed the now famous 'central dogma' according to which information so defined flows between the nucleic acids and proteins only in one direction - from the former to the latter ${ }^{16}$. Just four years later, Marshall Nirenberg and Heinrich Matthaei successfully synthesized a polypeptide constituted of only one kind of amino acid (phenylalanine) using an RNA composed only of one kind of base (uracil). They concluded that "one or more [of these RNA bases] appear to be the code for phenylalanine." ${ }^{\prime 7}$ Meanwhile, Crick, Sydney Brenner and Leslie Barnett had been using genetic analysis to investigate mutagenesis. This led them to the important concept of a form of mutation in which there is a 'frame shift' in the sequence of the bases in DNA, from which they went on to infer that the genetic message is composed of single or multiple triplets of bases, and that the message is read starting at a fixed point and proceeds always in the same
Six of the Nobel winners of 1962 display their diplomas after formal ceremonies in Stockholm's Concert Hall. From left to right: Maurice Wilkins (Medicine), Max Perutz (Chemistry), Francis Crick (Medicine), John Steinbeck (Literature), James Watson (Medicine) and John Kendrew (Chemistry).

Figure 1 Papers published in Nature referring to DNA and the extent of their reference to the double helix 1950-1960.

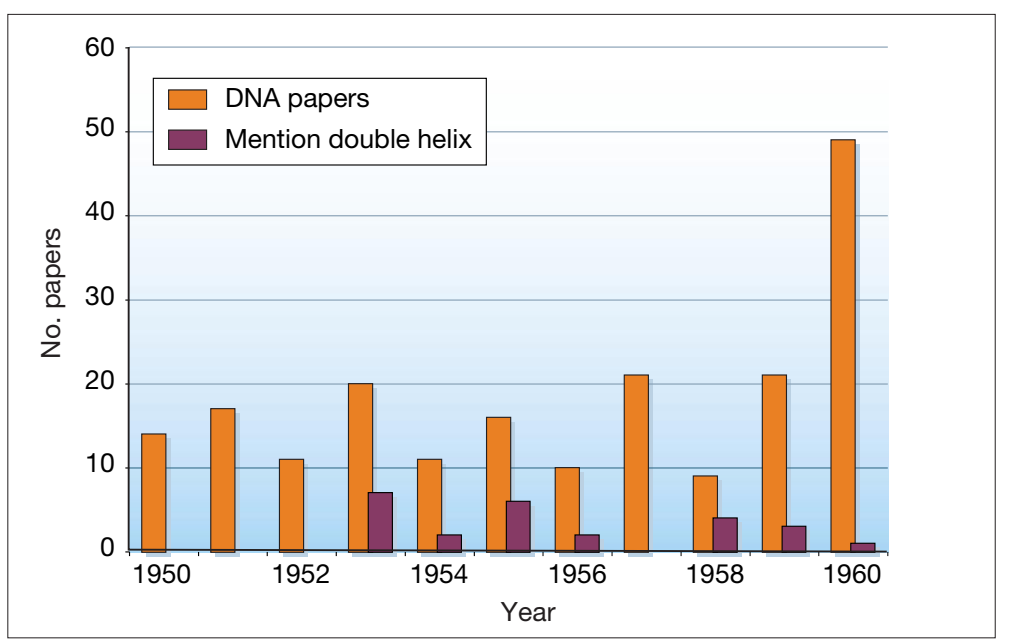


Box 1

Time line of the discovery of the structure of DNA

1869 Fritz Miescher discovers that the nuclei of pus cells contain an acidic substance to which he gave the name 'nuclein'. Later he finds that nuclein is composed of a protein and a compound to which the name nucleic acid, and subsequently DNA, will be given.

1919 Phoebus Aaron Levene proposes the 'tetranucleotide' structure of DNA, whereby the four bases of DNA were arranged one after another in a set of four.

1928 Frederick Griffith finds that a substance in heat-killed bacteria can cause heritable changes in the live bacteria alongside them. He calls the phenomenon 'transformation'.

1938 Rudolf Signer, Torbjorn Caspersson and Einer Hammarsten find molecular weights for DNA between 500,000 and 1,000,000 daltons. Levene's tetranucleotide must be a polytetranucleotide.

1944 Oswald Avery, Colin MacLeod and Maclyn McCarty establish the chemical identity of Griffith's transforming principle as DNA, and they suggest that it may function as the genetic material.

1949 Erwin Chargaff reports that DNA base composition varies from one species to another, yet the ratio between the quantities of the two purine bases, adenine and thymine, and that between the quantities of the two pyrimidine bases, guanine and cytosine, remains about the same, namely one to one.

1949 Roger and Colette Vendrely, together with André Boivin find half as much DNA in the nuclei of sex cells as they find in the body cells, thus paralleling the reduction in the number of chromosomes, making DNA look like the genetic material.

1951 Rosalind Franklin distinguishes two forms of DNA, the paracrystalline B form and the crystalline A form.

1952 Al Hershey and Martha Chase find that DNA but scarcely any protein from an infecting bacterial virus enters the bacterial cell and can be recovered from the progeny virus particles.

1952 Rosalind Franklin and Raymond Gosling produce a magnificent X-ray diffraction pattern of the $B$ form of DNA.

1953 James Watson and Francis Crick, Rosalind Franklin and Raymond Gosling, Maurice Wilkins, W. E. Seeds, Alec Stokes and Herbert Wilson, and Bertil Jacobson all publish on the structure of $\mathrm{DNA}^{2-8}$.

1954 George Gamow suggests a DNA code for the synthesis of proteins.

1955 Seymour Benzer analyses the fine structure of the genetic material of a bacterial virus at a level close to the distances that separate the individual bases along the DNA chain.

1957 Francis Crick proposes 'the sequence hypothesis' and 'the central dogma'.

1958 Matthew Meselson and Franklin Stahl demonstrate the semi-conservative replication of DNA.

1959 Arthur Kornberg and colleagues isolate the enzyme DNA polymerase.

1961 Marshall Nirenberg and Johann Heinrich Matthaei show that a sequence of nucleotide can encode a particular amino acid, laying the foundations for deciphering the genetic code.

1962 The Nobel prize in medicine is awarded to James Watson, Francis Crick and Maurice Wilkins.
Alexander Dounce, did not refer to the structure in their scientific papers in the mid-fifties, even though it was clearly relevant and presumably known to them. Such omissions suggest that some biochemists had their own agendas, and the double helix was not at first seen as an aid to their work.

\section{Biochemists debate protein synthesis}

Biochemists' reservations about the double helix stemmed in part from the fact that evidential support for it in 1953 was far from strong. Watson and Crick themselves admitted that it "could in no sense be considered proved", although it was "most promising"19. In part the biochemists' coolness owed much to the debates among them over the mechanism of protein synthesis. The paper by Peter Campbell and Thomas Work, published in Nature on 6 June 1953, portrayed this debate vividly. They identified two contrasting theories under discussion on how proteins are made: first, the peptide theory (also known as the multienzyme theory), where proteins are made by "stepwise coupling of many small peptide units"; and second, the template theory, involving "synthesis on templates, each template being specific for a single protein structure and probably identifiable as a gene." 20

The peptide model was, for a very long time, supported by many prominent biochemists, including Joseph Fruton. The conviction behind it was the power of enzymes to both synthesize and break down their substrates, with a high degree of specificity attributed to both actions. Synthesis was proposed to involve the formation of a succession of peptides, ultimately yielding the protein molecule, and enzymes synthesize only those peptide bonds that they also hydrolyse. But the problem with this theory was that, except for a very few special cases, the alleged peptides constituting the intermediaries in protein synthesis could neither be detected in the cell nor incorporated into the protein being synthesized. Amino acids, however, could be incorporated, indicating they were the building blocks of proteins.

The second model of protein synthesis, which assumed synthesis on a template, had been advocated by Dounce in 1952. He pictured polypeptide chains being laid down on RNA molecules, and the RNA sequence determining the sequence of amino acids incorporated (on a one-to-one basis). Thus, DNA in the nucleus would control the order of bases in the RNA ${ }^{21}$.

After weighing up the merits and difficulties of Dounce's scheme, Campbell and Work voiced their distaste for the genetic control of protein synthesis, remarking in 1953 that: "...the gene is essentially an abstract idea and it may be a mistake to try to clothe this idea in a coat of nucleic acid or protein... if we must have a gene it should have a negative rather than a positive function so far as protein synthesis is concerned." ${ }^{20}$ Only three years later, however, Robert Sinsheimer concluded a lecture at the California Institute of Technology with the following words: "The gene, once a formal abstraction, has begun to condense, to assume form and structure and defined activity." ${ }^{1}$

But those three years were a scene of pronounced change. By January 1957, when Fruton revised the second edition of his widely used textbook General Biochemistry, his remarks on the peptide theory were 
cautious and were followed by a discussion of the role of RNA on which, he noted, there have been "stimulating speculations about the role of nucleic acids as 'templates' in protein synthesis." ${ }^{\prime 2}$ Earlier in the book he devoted a paragraph to the double helix, describing it as an 'ingenious speculation'. The only diagram was of the base pair adenine-guanine, rather than the helical model of the structure.

Kornberg had shown in 1957 that DNA replication follows the rules of base pairing, whereby DNA polymerase adds a base to the newly synthesized strand that is complementary to the opposing base in the template strand ( $\mathrm{A}$ is always opposite $\mathrm{T}$, and $\mathrm{C}$ always opposite $G$ ). But his interest in the subject had not been stimulated by Watson and Crick's discovery. Rather, in 1953 he was preoccupied with how coenzymes (non-protein compounds needed for enzyme activity) are synthesized from nucleotides. He was led to wonder how DNA and RNA might be made from thousands of nucleotides. "The significance of the double helix," he recalled, "did not intrude" into his work until 1956, after he had shown that a "moderately purified fraction" of what he was later to call DNA polymerase "appeared to increase the size of a DNA chain." 23,24

\section{Conclusion}

The two once enigmatic processes - DNA replication and protein synthesis - intersected ongoing research programmes in the physical, organic and biological chemistry of the early 1950s. After the discovery of the double helix, those grappling with the problem of replication found its molecular foundation in the structure of DNA, although it took more than two decades to deduce the intricate mechanism of its operation in the cell (see article in this issue by Alberts, page 431). Those working on protein synthesis found the source of its specificity lay in the base sequence of DNA.

But why celebrate this one discovery? Why not celebrate the golden jubilee of Max Perutz's solution to the 'phase problem' for proteins in 1953, without which the subsequent discovery of the structure of myoglobin and haemoglobin would not have been possible? What about the year 2005 for celebrating the golden jubilee of Sanger's determination of the complete amino-acid sequence of a protein? Undoubtedly, the double helix has remarkable iconic value that has contributed significantly to its public visibility, something that has not been achieved by any of the protein structures (see article in this issue by Kemp, page 416). There is, too, a degree of notoriety attaching to the manner of its discovery and the characters involved that has given spice to the story, as widely publicized by James Watson's account of the discovery in The Double Helix, published in 1968 (ref. 25), and Brenda Maddox's recent illuminating biography of Rosalind Franklin ${ }^{26}$. But there is a centrality about DNA that relates to the centrality of heredity in general biology.
The silver and golden jubilees of the Queen's accession to the throne have come and gone, nuclear power stations are no longer being built in the United Kingdom, and mountaineer after mountaineer has ascended Mount Everest without a fanfare of press reports. But DNA is very much in the news - whether it be as a tool for studying evolution, a forensic test for rape, a source of genetic information or a path to designer drugs. And what better emblem or mascot is there for molecular biology than the double helix, and its spartan yet elegant representation in the original paper ${ }^{2}$ from the pen of Odile Crick, Francis's wife, fifty years ago?

doi:10.1038/nature01397

1. Sinsheimer, R. L. First steps toward a genetic chemistry. Science 125 , 1123-1128 (1957)

2. Watson, J. D. \& Crick, F. H. C. A structure for deoxyribose nucleic acid. Nature 171, 737-738 (1953).

3. Wilkins, M. H. F., Stokes, A. R. \& Wilson, H. R. Molecular structure of deoxypentose nucleic acids. Nature 171, 738-740 (1953).

4. Franklin, R. E. \& Gosling, R. G. Molecular configuration in sodium thymonucleate. Nature 171, 740-741 (1953).

5. Watson, J. D. \& Crick, F. H. C. Genetical implications of the structure of deoxyribonucleic acid. Nature 171, 964-967 (1953).

6. Franklin, R. E. \& Gosling, R. G. Evidence for 2-chain helix in crystalline structure of sodium deoxyribonucleate. Nature 172, 156-157 (1953)

7. Jacobson, B. Hydration structure of deoxyribonucleic acid and its physicochemical properties. Nature 172, 666-667 (1953).

8. Wilkins, M. H. F., Seeds, W. E., Stokes, A. R. \& Wilson, H. R. Helical structure of crystalline deoxypentose nucleic acid. Nature 172, 759-762 (1953).

9. Calder, R. Why you are you: nearer the secret of life. News Chronicle p. 1 (15 May 1953).

10. Avery, O. T. MacLeod, C. M. \& McCarty, M. Studies of the chemical nature of the substance inducing transformation of pneumococcal types. Induction of transformation by a desoxyribonucleic acid fraction isolated from Pneumococcus Type III. J. Exp. Med. 79, 137-158 (1944).

11. Hershey, A. D. \& Chase, M. Independent functions of viral proteins and nucleic acid in growth of bacteriophage. J. Gen. Physiol. 36, 39-56 (1952).

12. Watson, J. D. \& Crick, F. H. C. The structure of DNA. Cold Spring Harb. Symp. Quant. Biol. 18, 123-131 (1953).

13. Meselson, M. \& Stahl, F. W. The replication of DNA in Escherichia coli. Proc. Natl Acad. Sci. USA 44, 671-682 (1958).

14. Lehman, I. R., Bessmanm, M. J., Simms, E. S. \& Kornberg, A. Enzymatic synthesis of deoxyribonucleic acid. I. Preparation of substrates and partial purification of an enzyme from Escherichia coli. J. Biol. Chem. 233, 163-170 (1958).

15. Kornberg, A. Biological synthesis of deoxyribonucleic acid: an isolated enzyme catalyzes synthesis of this nucleic acid in response to directions from preexisting DNA. Science 131, 1503-1508 (1960).

16. Crick, F. H. C. On protein synthesis. Symp. Soc. Exp. Biol. 12, 138-163 (1958)

17. Nirenberg, M. W. \& Matthaei, J. H. The dependence of cell-free protein

synthesis in E. Coli upon naturally occurring or synthetic polynucleotides. Proc. Natl Acad. Sci. USA 47, 1558-1602 (1961).

18. Crick, F. H. C., Barnett, L., Brenner, S. \& Watts-Tobin, R. J. General nature of the genetic code for proteins. Nature 192, 1227-1232 (1961).

19. Crick, F. H. C. \& Watson, J. D. The complementary structure of deoxyribonucleic acid. Proc. R. Soc. Lond. A 223, 80-96 (1954)

20. Campbell, P. N. \& Work, T. S. Biosynthesis of proteins. Nature 171, 997-1001 (1953)

21. Dounce, A. Duplicating mechanisms for peptide chain and nucleic acid synthesis. Enzymologia 15, 251-258 (1952).

22. Fruton, J. S. General Biochemistry 2nd edn (Wiley, New York 1958).

23. Kornberg, A. For the Love of Enzymes. The Odyssey of a Biochemist (Harvard Univ. Press, Cambridge, MA, 1989).

24. Kornberg, A. in A Symposium on the Chemical Basis of Heredity (eds McElroy, W. D. \& Glass, B.) 605 (Johns Hopkins Press, Baltimore, 1957).

25. Watson, J. D. The Double Helix: A Personal Account of the Discovery of the Structure of DNA (Atheneum, New York, 1968). [Norton Critical Edition (ed. Stent, G. S.) published by Norton, New York \& London, 1980.]

26. Maddox, B. Rosalind Franklin. The Dark Lady of DNA (Harper Collins, London 2002). 